\title{
Gender differences in depressive symptoms of rural Chinese grandparents caring for grandchildren
}

Dantong Zhao ${ }^{1}$, Zhongliang Zhou ${ }^{1 *}$, Chi Shen ${ }^{1}$, Sahardid Ibrahim¹, Yaxin Zhao², Dan Cao ${ }^{1}$ and Sha Lai

\begin{abstract}
Background: Caring for grandchildren is regarded as one of the principle roles of middle- and old-aged adults, especially among rural Chinese grandparents. This study aims to examine the gender differences in depressive symptoms of rural Chinese grandparents caring for grandchildren, based on the gender differences in grandparental role engagement and the theories of role strain and role enhancement.

Methods: A total of 4833 rural citizens with one or more grandchildren were selected from the China Health and Retirement Longitudinal Study (CHARLS) conducted in 2015. Grandchild care was measured by continuous variable (duration) and categorical variable (no care, low intensity, moderate intensity, high intensity). Depressive symptoms were assessed by the Center for Epidemiologic Studies Depression Scale (CES-D). We used coarsened exact matching (CEM) to balance the covariates of caregivers and non-caregivers. Following CEM, 1975 non-caregivers and 2212 caregivers were identified $(N=4187)$. Multilevel linear regression was employed to examine the gender differences in depressive symptoms. We also tested for the moderating role of gender on the association between grandchild care and depressive symptoms.
\end{abstract}

Results: Grandmothers were more likely to provide grandchild care (54.42\% vs $51.43 \%$ ) at high intensity (61.46\% vs $51.01 \%$ ), with longer duration ( $39.24 \mathrm{~h}$ vs $33.15 \mathrm{~h}$ ) than that given by grandfathers. Grandmothers suffered more from depressive symptoms than grandfathers, and such gap increased when grandparents were involved in high-intensity care. Grandmothers providing grandchild care, particularly at moderate intensity, were associated with fewer depressive symptoms (Coef. $=-0.087,95 \% \mathrm{Cl}$ : $-0.163,-0.010$; Coef. $=-0.291,95 \% \mathrm{Cl}:-0.435,-0.147$ ), compared with non-caregivers. Grandmothers giving moderate intensity of grandchild care were also associated with fewer depressive symptoms (Coef. $=-0.171,95 \% \mathrm{Cl}:-0.313,-0.029)$, compared with those with low-intensity care. However, such associations were not significant among grandfathers.

Conclusions: Our findings highlight the gender differences in depressive symptoms of rural Chinese grandparents caring for grandchildren. Grandparents should be encouraged to engage in grandchild care, but at moderate intensity. The health status of middle- and old-aged adults, particularly females, should be monitored closely. Humanistic care, preventive care and curative treatment strategies focusing on such populations should be developed and refined.

Keywords: Gender differences, Depressive symptoms, Grandchild care, Intensity, Rural China

\footnotetext{
*Correspondence: zzliang1981@163.com

${ }^{1}$ School of Public Policy and Administration, Xi'an Jiaotong University, No. 28 Xianning West Road, Xi'an 710049, Shaanxi, China

Full list of author information is available at the end of the article
}

(C) The Author(s). 2021 Open Access This article is licensed under a Creative Commons Attribution 4.0 International License, which permits use, sharing, adaptation, distribution and reproduction in any medium or format, as long as you give appropriate credit to the original author(s) and the source, provide a link to the Creative Commons licence, and indicate if changes were made. The images or other third party material in this article are included in the article's Creative Commons licence, unless indicated otherwise in a credit line to the material. If material is not included in the article's Creative Commons licence and your intended use is not permitted by statutory regulation or exceeds the permitted use, you will need to obtain permission directly from the copyright holder. To view a copy of this licence, visit http://creativecommons.org/licenses/by/4.0/. The Creative Commons Public Domain Dedication waiver (http://creativecommons.org/publicdomain/zero/1.0/) applies to the data made available in this article, unless otherwise stated in a credit line to the data. 


\section{Background}

Grandparental childcare is a prevalent form of informal caregiving around the world and one of the main social roles for middle- and old-aged adults $[1,2]$. In the West, grandparents usually become caregivers to their own children's offspring when the adult children are afflicted by any of a number of common problems, including physical or mental illness, drug or alcohol addiction, teen pregnancy, imprisonment, unemployment and fulltime work [3-5]. In Europe, grandparents often play a role in childcare when there is limited access to formal childcare institutions, or adult children are affected by commitment to full-time work or by divorce [6]. In Black South African families, looking after young children is more accepted by grandparents because they regard grandparenting as a 'natural' responsibility [7]. Similarly, in Asian countries, especially China, grandparents take grandchild care for granted, not only because of common multigenerational family structures and financial supports from adult children (grandchild care is a form of "time-for-money" exchange in some cases), but also as inherited duties derived from traditional and cultural norms $[1,8]$. Such customs of multigenerational co-residence and traditional cultural values are validated by the ancient Chinese belief system of Confucianism, which highlights the importance of familial harmony [9] and places great emphasis on the significance of Chinese grandparents' providing grandchild care.

In the context of the dual Chinese urban-rural social structure, it is easier for rural grandparents to provide custodial grandchild care; urban grandparents are more likely to provide part-time care or supplementary assistance. Despite the rapid urbanization process and unprecedented economic growth have eroded traditional cultural values to some extent, rural residents still observe traditional practices in accordance with inherited norms and beliefs, unlikely many urban residents [10]. Compared with their urban counterparts, Chinese grandparents in rural areas are more likely to be involved in intensive caregiving because of the massive rural-urban migration of the labour force in recent decades [11] and the prevailing preference of intergenerational co-habitation and mutual financial support as the key to 'family prosperousness' [12]. Moreover, rural grandparent caregivers are more likely to develop medical problems than their urban peers because of intensive caregiving and a lack of healthcare resources, supporting alternative childcare facilities and other community-based support services or programs [1]. Consequently, we focus on the health of rural Chinese grandparents in this study.

Grandchild care and grandparents' depressive symptoms Depression, a non-communicable disease, is globally prevalent regardless of gaps in economic development
[13], and social and cultural factors in various regions [14]. It is evidenced that depression can be a contributory cause of numerous physical health problems, such as inflammation [15], Parkinson disease [16], type-2 diabetes [17] and cardiovascular disease [18], resulting in an increasing burden being placed on individual families and communities, as well as affecting statistics at national level. Moreover, globally, depression is most common in middle- and old-age [13, 19]. As the Chinese population ages rapidly, there is an increasing interest in literature on depressive symptoms of grandparents caring for grandchildren. The literature indicates that caring for grandchildren contributed to reduced depressive symptoms in grandparents in some countries [8, 20, 21], the same scenario is seen in China [22-24]. Based on the theory of role enhancement, multiple social roles lead to improved wellbeing, since individuals gain social integration and gratification from these different areas of social participation $[25,26]$. As a type of social role, caring for grandchildren provides grandparents with stronger and more frequent emotional connections with the younger generation and more opportunities for receiving informal and formal support and forging social bonds [27]. According to the existing literature and the theory of role enhancement, we therefore expect that rural Chinese grandparents providing grandchild care have fewer depressive symptoms, compared with those who do not.

\section{Grandchild-care intensity and grandparents' depressive symptoms}

Despite the evidence that caring for grandchildren relieves grandparents' depressive symptoms, a few studies still show it to have an overall negative effect [28-30], mainly owing to the added stress involved in caregiving. Role strain theory argues that, when individuals play multiple social roles and undertake a series of social obligations, negative health problems can result when they exceed their physical and psychological capabilities [31, 32]. Following the theory of role strain, the heterogeneous findings in the literature regarding the association between grandchild care and grandparents' depressive symptoms can be explained by the intensity of grandchild-care involvement. Caring for grandchildren may become a stressful and potentially overwhelming task that can have dire consequences for the physical and psychological health of the individual, particularly for grandparents providing extensive care [33], as they find they have little energy and limited time to maintain other personal social activities or social ties [34]. Studies have shown that high intensity of caregiving is more likely to damage the cognitive health of grandparents [35] and indicate a decline in self-reported health [1]. However, a reduction in care intensity was associated with an increase in life satisfaction in the middle-aged 
and elderly population in China [36]. Moreover, less intensive grandchild care was demonstrated to have an association with a reduction in depressive symptoms for grandparents in France [37]. Meanwhile increasing grandchild care to an intensive level increased depressive symptoms among grandmothers in Poland, Spain and Sweden [37]. The association between intensity of grandchild care and depressive symptoms of caregivers is seen across Western countries. We hypothesize that moderate-intensity grandchild care is likely to result in fewer depressive symptoms, whereas high-intensity grandchild care is associated with more depressive symptoms for rural grandparents in China.

\section{Gender context}

Despite the well-established association between depressive symptoms and grandparents caring for grandchildren, and multiple influencing factors on caregivers' depressive symptoms (including demographic characteristics, health status and social participation of the caregiver, grandchildren's characteristics and living arrangements), most of them did not distinguish between grandmothers and grandfathers. $\mathrm{Al}$ though important gender differences were found in the grandchild-care experience [38-40] and depressive symptoms were different for males and females [28, 41], most studies analysed grandparents as a demographic group, preventing us from determining a gender differential effect in grandchild-care involvement and depressive symptoms. Given that there are gendered responsibilities and expectations [42], grandmothers usually provide a greater portion of grandchild care than do grandfathers [38, 39, 43]. Empirical evidence on the association between grandchild care and grandparents' mental health suggests that grandmothers who provide grandchild care are not only at lower risk of depression than those who do not [20], but also experience a higher level of life satisfaction $[9,44]$ than do grandfathers. Another study using the longitudinal structure of the Survey of Health, Ageing and Retirement in Europe (SHARE) showed a reduction in depressive symptoms in grandmothers who became caregivers [37]. Based on previous evidence around the grandparental role in grandchild care, and depressive symptoms of grandparents caring for grandchildren (considering gender difference), we therefore hypothesize that grandmothers had more depressive symptoms than grandfathers, and grandmothers rather than grandfathers caring for grandchildren are significantly associated with depressive symptoms in rural China.

We attempt to contribute to the literature on grandchild care and depressive symptoms among grandparents by examining the gender differences in depressive symptoms of rural Chinese grandparents caring for grandchildren, using nationally representative data. We propose the following hypotheses: (1) compared with non-caregivers, caregivers are expected to have fewer depressive symptoms; (2) caregivers providing nonintensive of grandchild care are expected to have fewer depressive symptoms, whereas those with intensive grandchild-care involvement are likely to have more depressive symptoms; (3) the above associations are applicable to grandmothers rather than grandfathers; (4) grandmothers suffer more from depressive symptoms than grandfathers.

\section{Methods \\ Data and sample}

Data for this study were drawn from the China Health and Retirement Longitudinal Study (CHARLS) conducted in 2015, a nationally representative survey targeting middle- and old-aged adults in China. CHARLS 2015 surveyed 21,789 individuals selected from 450 villages/resident committees in 150 counties/districts in 28 provinces across the country, using a four-stage, stratified, cluster sampling method to select reviewers. The detailed sampling design had been introduced previously $[45,46]$. The present study selected grandparents registered as the 'Agricultural Hukou' under the Hukou household-registration system [47], with at least one grandchild under 16 years old [27], so as to avoid the possible selection bias suggesting that people without grandchildren are inherently different from those who have grandchildren in terms of health status [48]. Hukou divides Chinese citizens into two categories, with Agricultural Hukou for households in rural areas and Nonagricultural Hukou for those in urban areas [49]. Excluding missing values, the study sample contained 4833 individuals.

\section{Measurement}

Depressive symptoms served as a dependent variable in this study, measured by the 10-item Center for Epidemiologic Studies Depression Scale (CES-D). The respondents were required to assess their mental and emotional states accurately during the week prior to the interview. Each item used a four-point Likert scale, with an answering category ranging from "Rarely or none of the time $(<1$ day)" to "Most or all of the time (5-7 days)", coding from 0 to 3 . The sum score ranged from 0 to 30 , with higher values presenting more depressive symptoms. Previous studies suggest that CES-D has good reliability and validity among the Chinese population [50]. According to previous studies that a cut-off point of 12 provides the optimal threshold by which to identify clinically significant depression [51, 52], a score of 12 was also used in this study to generate a binary depression variable $(\mathrm{No}=0$, Yes $=1)$. It was used to describe further the prevalence of grandparents' depression. In order to make the continuous variable CES-D score normally distributed to fit the regression, 
we transferred the CES-D score to its square root. As Fig. 1 shows, the distribution of its square root was broadly normally distributed, although it skewed slightly left (skewness $=-0.28$ and kurtosis $=2.78)$ [53].

Grandchild care was an independent variable in this study, measured by three indicators. One was grandparents' self-reported answer to the question, "Did you spend any time taking care of your grandchildren last year", which was divided into 'Non-caregivers' and 'Caregivers', a binary variable. The other was the answer to the question, "Approximately how many hours per week did you spend last year on taking care of grandchildren", which was regarded as a continuous variable (duration) and a categorical variable (no care, low intensity, moderate intensity, high intensity), respectively. Based on previous studies $[1,39,53,54]$, three categories of grandchild-care intensity were identified: low intensity (spending 1-14h per week), moderate intensity (spending $15-39 \mathrm{~h}$ per week) and high intensity (spending $\geq 40 \mathrm{~h}$ per week). The cut-off point of $15 \mathrm{~h}$ was referred to in the previous literatures [1,53], and $40 \mathrm{~h}$ was chosen based on standard working time per week (five-day working week and no more than $8 \mathrm{~h}$ a day) according to the Labour Law of China and previous studies $[55,56]$. The gender of grandparents was used to stratify the full sample into the grandfathers and grandmothers subsamples.

Control variables included age ( $45-59$ years old; $\geq 60$ years old); education level (illiterate; primary school or below; middle school; high school or above); marital status (separated/ divorced/widowed/never married; married); work status (unemployed/working); annual household income (poorest/ 2nd quintile/middle/4th quintile/richest); receiving intergenerational support from children (yes/no); co-habiting with children (yes/no); engaging in social activities (yes/no); suffering from chronic disease (yes/no); ADLs score; IADLs score; and number of grandchildren. Annual household income included individual and other household members' income (e.g., wages, assets, subsidies, government transfers and other income sources), which was divided into quintiles. Intergenerational support from children included cash and in-kind transfers. Engagement in social activities was defined as any activity participated in between individuals, such as interacting with friends; playing mah-jongg/chess/cards or attending community clubs; providing help for family/friends/neighbours outside the household; attending a sport/social/other club; taking part in community-related organizations; undertaking voluntary or charity work; caring for a sick or disabled adult outside the household; attending an educational or training course; stocking investment and using the internet. We considered using the internet as a type of social activity not only because it is one of the options to this question in the CHALRS questionnaire, but also because prior studies have categorised using the internet as a type of social activity, given that individuals can communicate and form social ties without being affected by limitations on mobility and activity for older adults, and it consequently reduces social isolation, and enhances social integration and support [52, 57, 58]. ADLs score was the sum score of items asking interviewers whether they had difficulties with dressing, bathing or showering, eating, getting into or out of bed, using the toilet, and
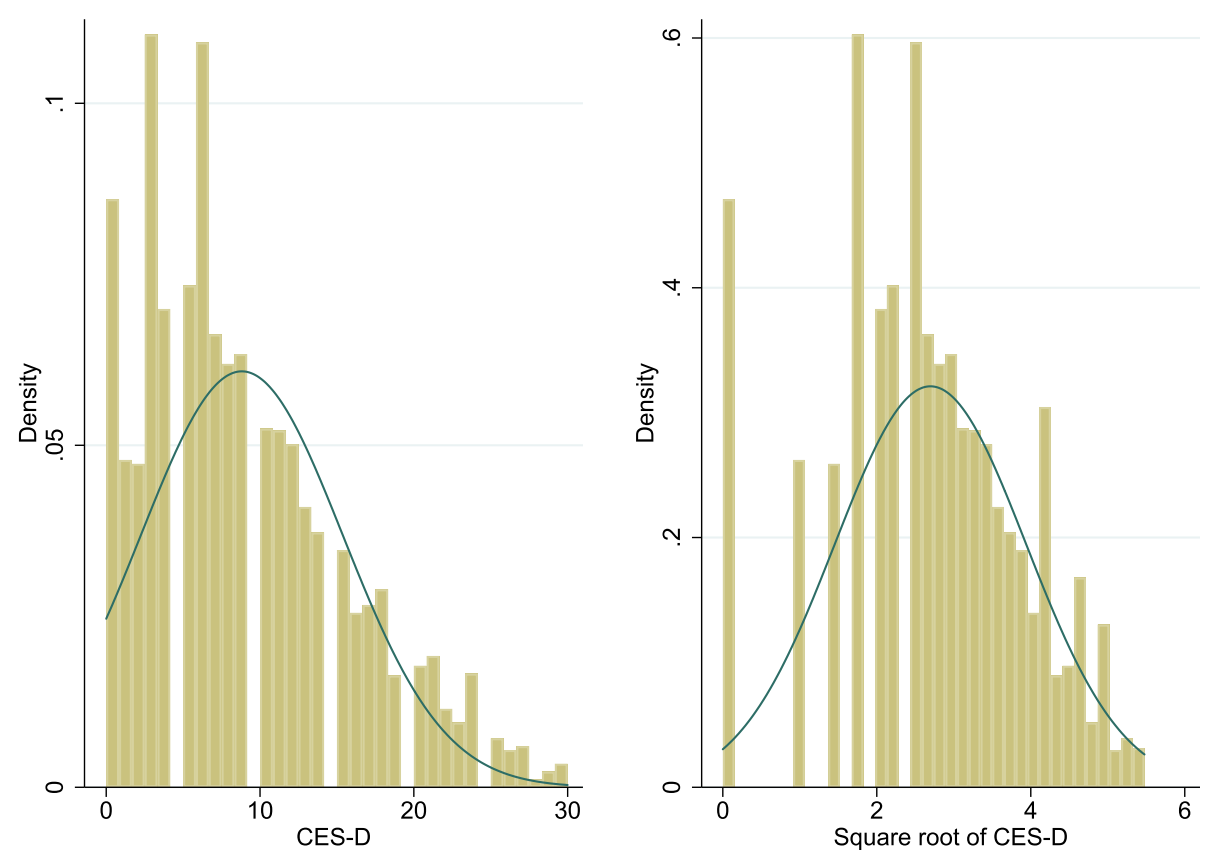

Fig. 1 Comparison of distribution of CES-D and its square root 
controlling urination and defecation, with each coding from 0 (no difficulties) to 3 (cannot perform it). IADLs score was measured by totalling the items asking respondents whether they encountered difficulties in performing household tasks, preparing hot meals, shopping for groceries, managing personal finances, making phone calls and taking medications, with the same coding as the former. Detailed definitions and codes of variables are presented in Table 1.

\section{Coarsened exact matching method}

Evidence shows that both matched sampling and regression adjustment can be expected to reduce bias [59]. Matching method application is more robust than regression analysis alone [60]. Initially, we used the Coarsened exact matching (CEM) method put forward by Iacus et al. $[61,62]$ to balance the multidimensional distribution of covariates between the two compared groups (non-caregivers and caregivers), and thereby reduce the explanatory variable's degree of dependence on the estimation model and further decrease the biases. CEM is a matching method of the class Monotonic Imbalance Bounding (MIB), which shows the basic advantage over other matching methods that the bound on balance for one covariate can be studied and improved in isolation, as this won't affect any other covariates chosen for balancing $[62,63]$. It is preferable to other matching procedures (e.g., propensity score matching, PSM) in terms of processing more efficiently and reducing model dependence, estimation error, variance and bias [64]. It does not require further conduct balance checking or restrict data to common support, as is required by PSM.

The CEM algorithm consists of three principal procedures [61]. Firstly, each variable is coarsened by recoding, and thereby indistinguishable values are grouped and allotted the same numerical value (groups may have the same or different sizes). Secondly, the coarsened data are matched using an "exact matching" algorithm, and unmatched units are pruned. Thirdly, the coarsened data are removed and the uncoarsened (original) values of the matched data are retained. Additionally, a CEMweights variable is generated to equalize the number of observations within comparison groups, where unmatched units are 0 and matched units are larger than 0 but less than 1 [61]. For balance checking of two compared groups, multivariate imbalance measure $\mathrm{L}_{1}$ is employed, of which size depends on the dataset and the variables selected. $\mathrm{L}_{1}$ ranges from 0 to 1 , where 0 and 1

Table 1 Definitions/codes of variables

\begin{tabular}{|c|c|}
\hline Variables & Definitions/codes \\
\hline CES-D & Continuous variable, $0-30$ \\
\hline Square root of CES-D & Continuous variable, $0-5.48$ \\
\hline Grandchild-care duration & Continuous variable, $0-168 \mathrm{~h}$ \\
\hline Grandchild-care provision & $\mathrm{No}=0, \mathrm{Yes}=1$ \\
\hline Grandchild-care intensity ${ }^{a}$ & $\begin{array}{l}\text { No care }=0, \text { Low intensity }=1 \text {, Moderate intensity }=2 \text {, } \\
\text { High intensity }=3\end{array}$ \\
\hline Grandchild-care intensity $^{\mathrm{b}}$ & Low intensity $=0$, Moderate intensity $=1$, High intensity $=2$ \\
\hline Age, years & $45-59$ years $=1, \geq 60$ years $=2$ \\
\hline Gender & Male $=0$, Female $=1$ \\
\hline Education level & $\begin{array}{l}\text { Illiterate }=1 \text {, Primary school or below }=2, \\
\text { Middle school }=3 \text {, High school or above }=4\end{array}$ \\
\hline Marital status & Separated/Divorced/Widowed/Never married $=0$, Married $=1$ \\
\hline Work status & Unemployed $=0$, Working $=1$ \\
\hline Annual household income & $\begin{array}{l}\text { Poorest }=1,2 \text { nd quintile }=2 \text {, Middle }=3,4 \text { th quintile }=4 \text {, } \\
\text { Richest }=5\end{array}$ \\
\hline Receiving intergenerational support from children & $\mathrm{No}=0, \mathrm{Yes}=1$ \\
\hline Co-habiting with children & $\mathrm{No}=0, \mathrm{Yes}=1$ \\
\hline Number of grandchildren & Continuous variable \\
\hline Engagement in social activities & $\mathrm{No}=0, \mathrm{Yes}=1$ \\
\hline Suffering from chronic disease & $\mathrm{No}=0, \mathrm{Yes}=1$ \\
\hline ADLs score & Continuous variable, $0-18$ \\
\hline IADLs score & Continuous variable, $0-18$ \\
\hline
\end{tabular}

ADLs Activities of Daily Living, IADLs Instrumental Activities of Daily Living

${ }^{\text {a Among all participates }}$

${ }^{\mathrm{b}}$ Among the caregivers 
represent perfect global balance and complete separation, respectively, and a larger value indicates greater imbalance between two groups. A good match usually reduces the value of $L_{1}[65]$. The $L_{1}$ statistic is calculated as follows [66]. Firstly, the covariates are coarsened into bins. Then, the discretized variables are cross-tabulated as $\mathrm{X}_{1} \times \ldots \ldots \times \mathrm{X}_{\mathrm{k}}$ for the treated and control groups, respectively, and k-dimensional relative frequencies are recorded for the treated $f_{\ell 1 \ldots \ell k}$ and the control $\mathscr{g} \ell$. . $\ell k$ units. Finally, the measure of imbalance is the absolute difference over all the cell values:

$$
\mathrm{L}_{1}(f, \mathscr{g})=\frac{1}{2} \sum_{\ell 1 \ldots \ell k}\left|f_{\ell 1 \ldots \ell k}-\mathscr{g} \ell 1 . \ell k\right|
$$

In the current study, we matched the socioeconomic characteristics and variables related to grandchild care according to the literature on CEM progress [53, 67], including age, education level, marital status, work status, annual household income, whether receiving intergenerational support from children, whether co-habiting with children, and number of grandchildren.

\section{The moderation effect and stratified analysis}

We first examined the moderation effect of gender on the association between grandchild care and depressive symptoms by creating interaction terms in multilevel linear regression. The predictive margins and the average marginal effects were presented to interpret the gender differences visually. Furthermore, taking gender differences in life expectancy (e.g., females generally live longer than males), socioeconomic status (e.g., males have higher educational attainment and better financial resources than females), and labour market (e.g., males have longer employment history than females) into account, we maintain that they are also likely to contribute to the gender gaps in the association between grandchild care and depressive symptoms. We therefore stratified the analyses by gender and further explored the possible gender differences in such an association.

\section{Statistical analysis}

The Chi-square test for categorical variables and Univariate ANOVA for continuous variables were used to compare caregivers and non-caregivers in the unmatched and matched cohorts. Matched weights were considered in all analyses in matched groups. Since the data of this study were drawn from CHARLS, with a four-stage stratified cluster sampling, the dependence among observations could exist on several levels of the hierarchy. To remove the cluster effect of observations at different levels of the data hierarchy [68], we fitted four-level multiple linear regression models (individual at level 1; nested within the community at level 2 ; nested within the city at level 3; nested within the province at level 4). An Intra-class Correlation Coefficient (ICC) is used to check the applicability and validity of the multilevel model. The ICC measures correlation among observations within a cluster, ranging from 0 to 1 . A multilevel regression model is appropriate for the analysis when ICC is greater than $0[68,69]$. In this study, the ICC values were $0.038,0.071$ and 0.113 in the grandfather subsample; and $0.023,0.060$ and 0.112 in the grandmother subsample, at province, city and community levels, respectively, which made multilevel linear regression suitable.

Subsequently, we examined the association between grandchild-care duration and depressive symptoms among all participants (including caregivers and noncaregivers) in Model 1; the association between grandchild-care provision and depressive symptoms among all participants in Model 2; and the association between grandchild-care intensity and depressive symptoms, respectively, among all participants in Model 3 and caregivers in Model 4, by using multilevel linear regression, controlling for grandparents' socioeconomic characteristics (including age, education level, marital status, work status, annual household income) and health status (including chronic disease, ADLs, IADLs), receiving intergenerational support from children, cohabiting with children, number of grandchildren and level of social engagement. Stata statistical software (version 15.0; StataCorp LP, College Station, Texas) was used for all analyses.

\section{Results}

Following the matching using CEM, 1975 non-caregivers and 2212 caregivers were identified for further analysis $(N=4187)$. The multivariate imbalance measure $\mathrm{L}_{1}$ was improved from 0.500 to nearly zero, and all variables matched were also close to zero, which indicated a good matching performance. Table 2 presents the basic characteristics of non-caregivers and caregivers before and after matching. It was clear that there were significant differences in most characteristics of non-caregivers and caregivers before matching. No statistical difference was found in any characteristics of non-caregivers and caregivers after the matching $(P>0.10)$, which further indicated that non-caregivers and caregivers were more comparable and balanced.

Overall, $52.83 \%$ of grandparents played a role in grandchild care, with an average of $36.00(\mathrm{SD}=52.35)$ hours per week. Grandmothers were more likely to provide grandchild care $(54.42 \%$ vs $51.43 \%)$ with longer duration $(39.24 \mathrm{~h}$ vs $33.15 \mathrm{~h})$, and they gave more care at high intensity $(61.46 \%$ vs $51.01 \%)$ than grandfathers.

Table 3 shows depressive symptoms of all participates, non-caregivers and caregivers, as well as those of 
Table 2 Basic characteristics of non-caregivers and caregivers in unmatched and matched cohorts

\begin{tabular}{|c|c|c|c|c|c|c|}
\hline \multirow[t]{2}{*}{ Variables } & \multicolumn{3}{|c|}{ Unmatched $(N=4833)$} & \multicolumn{3}{|l|}{ Matched $(N=4187)$} \\
\hline & $\begin{array}{l}\text { Non- caregivers } \\
\text { (\%) }\end{array}$ & Caregivers (\%) & $\begin{array}{l}P- \\
\text { value }\end{array}$ & $\begin{array}{l}\text { Non- caregivers } \\
(\%)\end{array}$ & Caregivers (\%) & $\begin{array}{l}P- \\
\text { value }^{c}\end{array}$ \\
\hline $\mathrm{N}$ & 2199 & 2634 & & 1975 & 2212 & \\
\hline $\mathrm{Age}^{\mathrm{a}}$, years & & & $<0.001$ & & & 0.993 \\
\hline $45-59$ & $711(32.33)$ & $1223(46.43)$ & & $881(44.62)$ & $987(44.62)$ & \\
\hline$\geq 60$ & $1488(67.67)$ & $1411(53.57)$ & & $1094(55.38)$ & $1225(55.38)$ & \\
\hline Education level $^{a}$ & & & $<0.001$ & & & 1.000 \\
\hline Illiterate & $650(29.56)$ & $663(25.17)$ & & $479(24.23)$ & $536(24.23)$ & \\
\hline Primary school or below & $1069(48.61)$ & $1203(45.67)$ & & 967 (48.96) & $1083(48.96)$ & \\
\hline Middle school & $361(16.42)$ & $560(21.26)$ & & $407(20.61)$ & $456(20.61)$ & \\
\hline High school or above & $119(5.41)$ & $208(7.90)$ & & $122(6.19)$ & $137(6.19)$ & \\
\hline Marital status ${ }^{a}$ & & & $<0.001$ & & & 0.983 \\
\hline Married & $582(26.47)$ & $411(15.60)$ & & $254(12.84)$ & $284(12.84)$ & \\
\hline Separated/Divorced/Wido-wed/Never married & $1617(73.53)$ & $2223(84.40)$ & & $1721(87.16)$ & $1928(87.16)$ & \\
\hline Work status $^{a}$ & & & $<0.001$ & & & 0.994 \\
\hline Unemployed & $712(32.38)$ & $690(26.20)$ & & $460(23.28)$ & $515(23.28)$ & \\
\hline Working & $1487(67.62)$ & $1944(73.80)$ & & $1515(76.72)$ & $1697(76.72)$ & \\
\hline Annual household income $e^{a}$ & & & $<0.001$ & & & 0.999 \\
\hline Poorest & $203.28(172.07)$ & $219.23(183.78)$ & & $212.12(173.27)$ & $220.90(183.18)$ & \\
\hline 2nd quintile & $1225.98(446.14)$ & $1198.56(442.78)$ & & $1304.82(467.74)$ & $1224.17(462.97)$ & \\
\hline Middle & $4622.72(1928.62)$ & $4687.21(1964.16)$ & & $4740.37(1886.45)$ & $4786.37(1959.94)$ & \\
\hline 4th quintile & $17,909.42(6331.63)$ & $\begin{array}{l}18,762.86 \\
(6572.85)\end{array}$ & & $17,893.18(6046.25)$ & $\begin{array}{l}18,599.94 \\
(6400.95)\end{array}$ & \\
\hline Richest & $\begin{array}{l}12,2600.7 \\
(414,961.1)\end{array}$ & $\begin{array}{l}101,823.9 \\
(184,383.4)\end{array}$ & & $\begin{array}{l}114,110.5 \\
(336,610.3)\end{array}$ & $\begin{array}{l}101,205.1 \\
(187,140.5)\end{array}$ & \\
\hline $\begin{array}{l}\text { Receiving intergenerational support from } \\
\text { children }^{a}\end{array}$ & & & 0.814 & & & 0.982 \\
\hline No & $312(14.19)$ & $380(14.43)$ & & $221(11.21)$ & $248(11.21)$ & \\
\hline Yes & $1887(85.81)$ & $2254(85.57)$ & & $1754(88.79)$ & 1964 (88.79) & \\
\hline Co-habiting with children ${ }^{a}$ & & & $<0.001$ & & & 1.000 \\
\hline No & $1514(68.85)$ & $1468(55.73)$ & & $1150(58.23)$ & $1288(58.23)$ & \\
\hline Yes & $685(31.15)$ & $1166(44.27)$ & & $825(41.77)$ & $924(41.77)$ & \\
\hline Number of grandchildren ${ }^{b}$ & $2.65(1.89)$ & $3.00(1.97)$ & $<0.001$ & $2.55(1.64)$ & $2.55(1.64)$ & 1.000 \\
\hline Engagement in social activities ${ }^{a}$ & & & 0.001 & & & 0.085 \\
\hline No & $1120(50.93)$ & $1211(45.98)$ & & $958(48.50)$ & $1014(45.84)$ & \\
\hline Yes & $1079(49.07)$ & $1423(54.02)$ & & $1017(51.50)$ & $1198(54.16)$ & \\
\hline Suffering from chronic disease ${ }^{a}$ & & & 0.048 & & & 0.923 \\
\hline No & $579(26.33)$ & $761(28.89)$ & & $575(29.11)$ & $647(29.25)$ & \\
\hline Yes & $1620(73.67)$ & $1873(71.11)$ & & 1400 (70.89) & 1565 (70.75) & \\
\hline ADLs score ${ }^{b}$ & $0.69(1.77)$ & $0.50(1.33)$ & $<0.001$ & $0.55(1.44)$ & $0.50(1.33)$ & 0.553 \\
\hline IADLs score ${ }^{b}$ & $1.34(2.78)$ & $1.03(2.32)$ & $<0.001$ & $1.09(2.41)$ & $1.02(2.35)$ & 0.113 \\
\hline
\end{tabular}

ADLs Activities of Daily Living, IADLs Instrumental Activities of Daily Living

${ }^{a}$ Chi-square test

bUnivariate ANOVA

${ }^{\mathrm{c} C o n s i d e r i n g ~ m a t c h}$ weights 
Table 3 Comparison of depressive symptoms across gender in matched cohorts

\begin{tabular}{|c|c|c|c|c|c|c|}
\hline \multirow[t]{3}{*}{ Variables } & \multirow{3}{*}{$\begin{array}{l}\text { Grandchild-care duration } \\
\text { Mean (SD) }\end{array}$} & \multicolumn{2}{|c|}{ Grandchild-care provision } & \multicolumn{3}{|c|}{ Grandchild-care intensity } \\
\hline & & Non-caregivers & Caregivers & Low & Moderate & High \\
\hline & & Mean (SD) & Mean (SD) & Mean (SD) & Mean (SD) & Mean (SD) \\
\hline \multicolumn{7}{|l|}{ Gender } \\
\hline \multirow[t]{2}{*}{ Male } & 7.55 & 7.82 & 7.32 & 7.15 & 7.34 & 7.35 \\
\hline & $(6.06)$ & $(6.14)$ & $(5.98)$ & $(5.81)$ & $(5.97)$ & $(6.04)$ \\
\hline \multirow[t]{2}{*}{ Female } & 10.23 & 10.62 & 9.91 & 9.90 & 9.39 & 10.08 \\
\hline & $(6.92)$ & $(7.10)$ & $(6.75)$ & $(7.07)$ & $(6.48)$ & $(6.73)$ \\
\hline$P$-value & $<0.001$ & $<0.001$ & $<0.001$ & $<0.001$ & $<0.001$ & $<0.001$ \\
\hline
\end{tabular}

Depressive symptoms were measured by CES-D

Univariate ANOVA was employed

caregivers with various levels of intensity across genders. Gender differences in depressive symptoms were found in each comparison group $(P<0.001)$, indicating that grandmothers had more depressive symptoms than grandfathers.

Figure 2 further presents depression prevalence of grandfathers and grandmothers caring for grandchildren. We found that grandmothers suffered from higher risks of depression than grandfathers (38.20\% vs $21.50 \%)$. Caregivers had lower depression prevalence compared with non-caregiver counterparts $(20.03 \%$ vs $23.50 \%$ among grandfathers, and $36.48 \%$ vs $40.26 \%$ among grandmothers). The more intensive the level of care that grandfathers provided, the higher the risk of depression (19.29\% vs $20.11 \%$ vs $20.24 \%)$. Grandmothers had the lowest risk of depression when participating in caregiving at moderate intensity (32.35\%).

Figure 3 presents the adjusted prediction margins for the interaction between gender and grandchild-care provision, intensity and duration. Gender played a moderating role on the association between care intensity and depressive symptoms. The negative interaction effect between moderate-intensity care and female suggested that grandmothers providing care at moderate intensity suffered fewer from depressive symptoms. Detailed results for the multilevel linear regression examining the moderation effect are reported in Table S1.

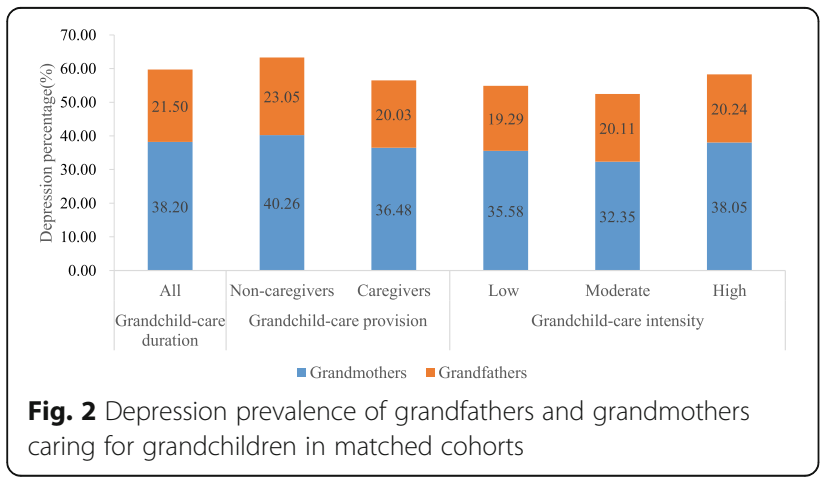

Figure 4 shows the average marginal effect of gender. The findings that the average marginal effects of gender were significantly greater than zero indicated that grandmothers had more depressive symptoms than grandfathers, except for those with moderate-intensity care. The gender difference diminished when grandchild careintensity increased from low to moderate. However, greater gender difference was found when intensity reached high level (see Fig. 4b).

Table 4 further shows the gender differences in depressive symptoms of grandparents caring for grandchildren, based on the grandfathers and grandmothers subsamples and using multilevel linear regression. We found that depressive symptoms were not significantly associated with grandchild-care duration (see Model 1), whereas they were correlated with care intensity (see Models 2, 3 and 4). Models 2 and 3 indicate that grandmothers providing grandchild care, particularly at moderate intensity, were associated with fewer depressive symptoms than non-caregivers $($ Coef. $=-0.087,95 \% \mathrm{CI}$ : $-0.163,-0.010$; Coef. $=-0.291,95 \% \mathrm{CI}:-0.435$, 0.147). Model 4 indicates that, compared with those with low care intensity, grandmothers with moderate intensity of grandchild care were associated with fewer depressive symptoms (Coef. $=-0.171,95 \% \mathrm{CI}:-0.313,-0.029)$, but those with high intensity of grandchild care were associated with more depressive symptoms, although the difference was not significant (Coef. $=0.110,95 \% \mathrm{CI}$ : $0.184,0.182)$. However, the above associations were not significant among grandfathers.

\section{Discussion}

In this study, we examine the gender differences in depressive symptoms of rural Chinese grandparents caring for grandchildren using nationally representative data. Consistent with hypothesis (1), grandmothers providing grandchild care were associated with fewer depressive symptoms compared with non-caregivers. Partly consistent with hypothesis (2), grandmothers with moderate intensity of grandchild care were associated with fewer 

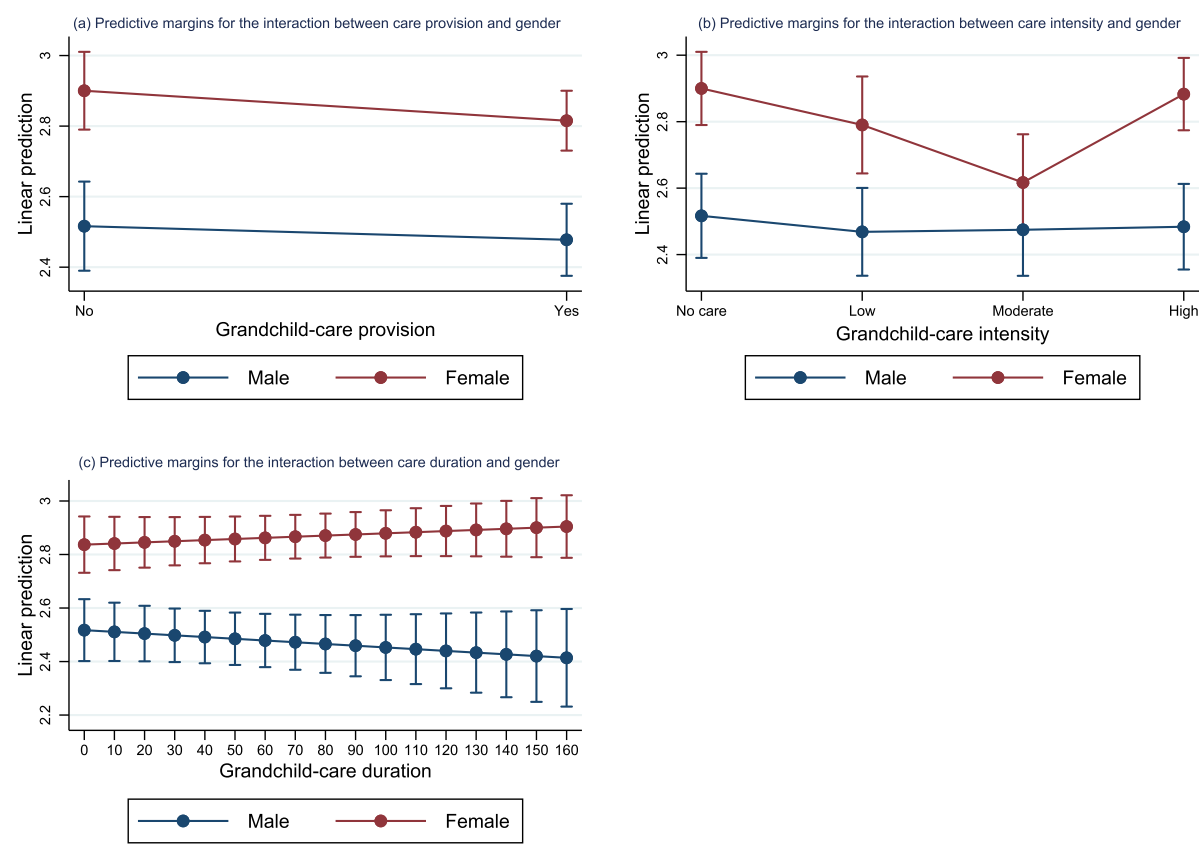

Fig. 3 Predictive margins for the interaction between gender and grandchild care in matched cohorts

depressive symptoms than those with low-intensity care. However, it was not strongly evidenced that grandmothers giving high-intensity care were likely to have more depressive symptoms. Consistent with hypothesis (3), the association between grandchild care and depressive symptoms was not significant among grandfathers. Moreover, grandmothers undertook more grandchild care and suffered more from depressive symptoms than did grandfathers.

As a consequence of increasing life expectancy, improved health of the elderly, and higher levels of divorce among modern adults, grandparents are becoming increasingly actively involved in family life around the world $[43,70]$. They play significant social roles in caring
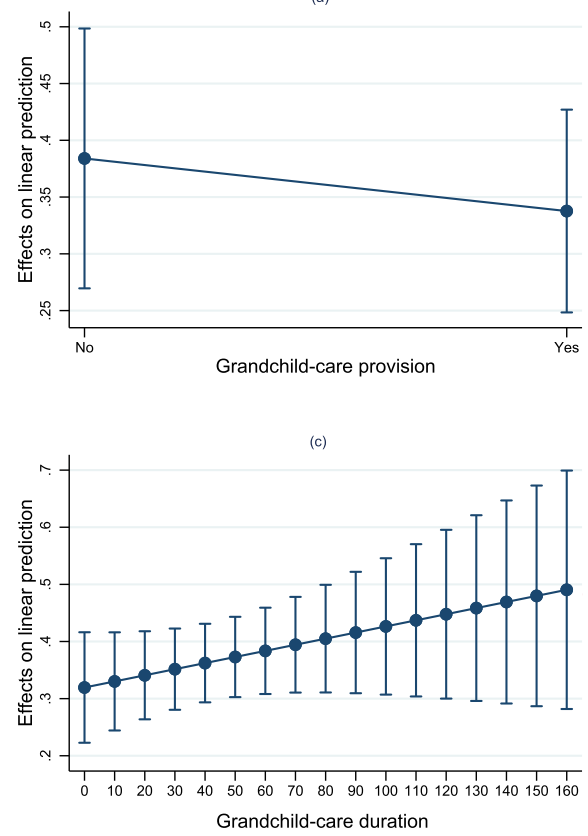

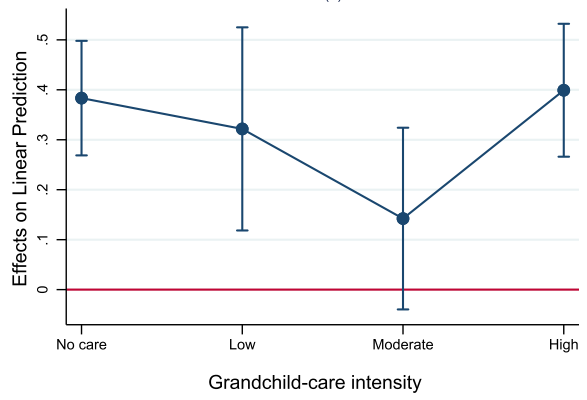

Fig. 4 Average marginal effects of gender in matched cohorts 


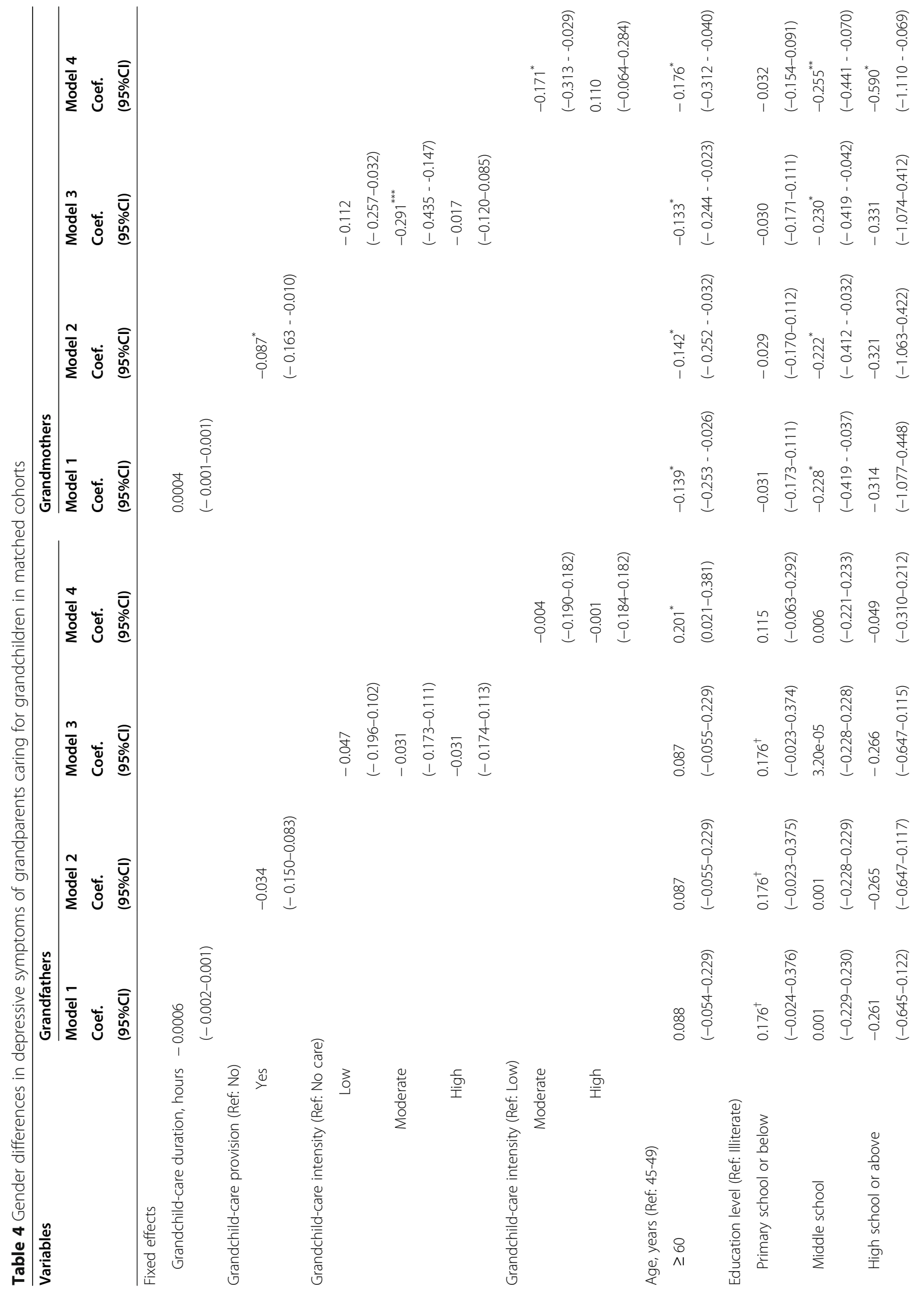




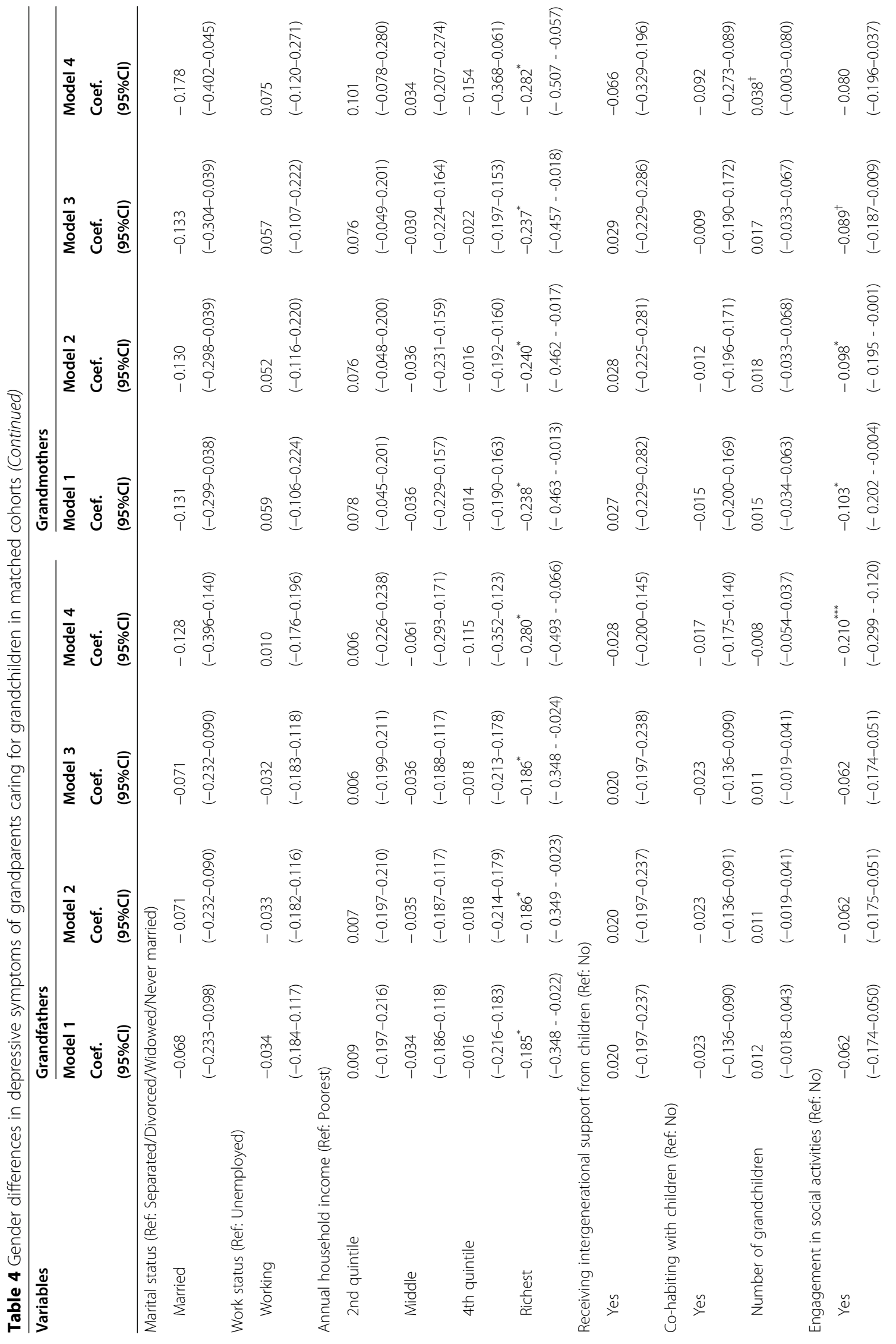




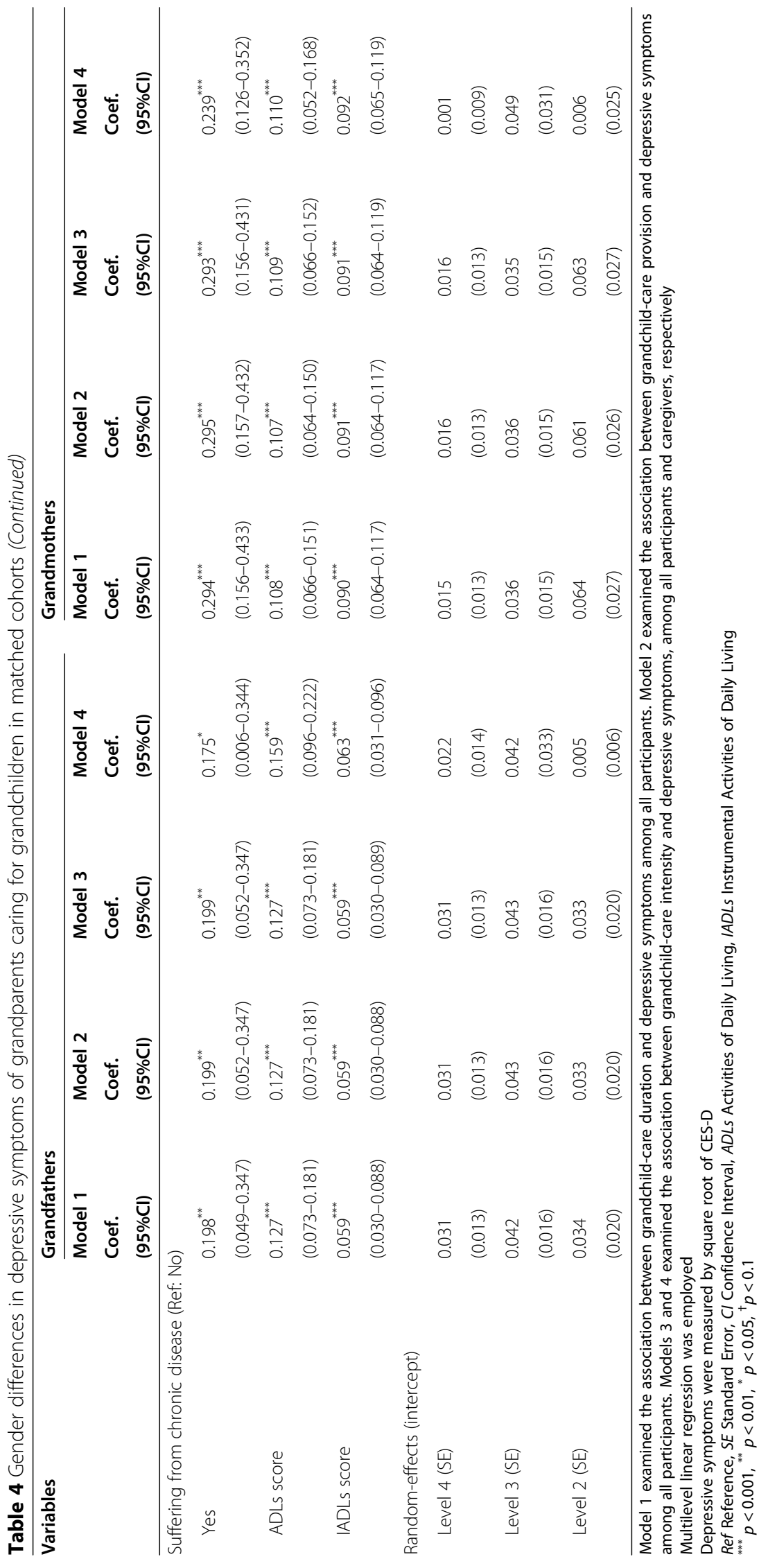


for grandchildren [53]. In a study of Israel and 17 European countries, nearly half of grandparents provided grandchild care [37]. In the US, $25 \%$ of children under the age of 5 have been cared for by grandparents [71]. The current study showed that over half of rural Chinese grandparents spent an average of $36.00 \mathrm{~h}$ per week taking care of grandchildren, much higher than Taiwanese (20.3\%) [8] and Korean grandparents (4.8\%) [54], as well as Chinese American (an average of $11.96 \mathrm{~h}$ a week) [27] and Spanish grandparents (an average of $23 \mathrm{~h}$ a week) [43]. In rural China, grandparents usually assume the duty of grandchild care to alleviate the burden on their adult children, particularly if the latter are employed [11, 35], since adult children often migrate from rural to urban locations to seek better employment opportunities and are obliged to leave their children with grandparents [36].

Grandmothers provided more hours of grandchild care than did grandfathers, in line with their Spanish peers [43]. They were also more likely to give grandchild care at high intensity than were grandfathers, similar to recent studies in China [9] and elsewhere in Europe [37]. This obvious gender-based gap presents an disparity of care assignment in rural Chinese society [72]. Females traditionally hold more responsibilities and obligations as 'kin keepers' [73]: they not only play with their grandchildren and take them on excursions, but also perform feeding, changing clothing/nappies, washing clothes and bathing with greater frequency than do grandfathers. Grandfathers typically play roles centred around entertainment and companionship [74, 75].

Moreover, grandmothers reported more depressive symptoms than grandfathers, and such differences increased when caregivers were involved in high intensity of care. A great number of studies have confirmed that females suffer more frequently from depressive symptoms $[43,76,77]$. Possible explanations for this are gender differences in terms of family/social involvement; feelings of responsibility in family matters; socioeconomic characteristics (e.g., education, income and marriage); social factors (e.g., social role, life events, social ties and social support); and psychological factors (e.g., vulnerability, mastery) $[78,79]$. When increasing care to intensive level, the above gender differences may become greater and lead to increased gaps in depressive symptoms. Therefore, we further stratified the analyses by gender so as to take gender differences in such aspects into account. We found a significant association between grandchild care and depressive symptoms among grandmothers, but not in grandfathers.

Grandmothers providing grandchild care, particularly at moderate intensity, had fewer depressive symptoms, consistent with a study in rural China [24]. This confirms the theory of role enhancement that grandparents gain significant psychosocial benefits from involvement in caregiving [67]. Grandparents' psychosocial benefits are mainly derived from emotional fulfillment rewards through participating in interactive intergenerational activities; learning opportunity rewards that come from having access to the use of mobile phones and the internet to maintain better contact with family and friends; and relation-oriented rewards in terms of increased selfesteem and self-confidence [80]. Moreover, grandchild care provides grandparents with new purpose in later life, reinforces bonds between family members, and enhances family happiness [29, 81, 82]. These positive events contribute to their being at lower risk of more depressive symptoms.

However, it is worth noting that high intensity of care was associated with more depressive symptoms among grandmothers, compared with those with low-intensity care, although this was not significant. Such possible association might be explained by the theory of role strain that mental health may be damaged if obligations of grandchild care exceed grandparents' physical and psychological resources (e.g., educational attainment, income and mental and physical health) [31]. High intensity of grandchild care usually leads to increased stress as a result of time pressure, exhaustion and loss of sleep [83]. It also results in strained relationships with spouses or children [84] and sacrifice of self-interest/ personal wellbeing [85]. The exertion and pressure associated with confronting and solving the problems that naturally arise in the course of grandchild care will eventually exact a toll on the health of the caregiver. Limiting grandparental involvement to moderate caregiving is beneficial to mental health, including alleviating depressive symptoms [1, 67]. Grandparents providing grandchild care should pay attention to the degree of care intensity and try to prevent care duties becoming a serious burden on them. However, whether excessive intensity of care is significantly associated with increased depressive symptoms, and the possible causal mechanisms for this are needed to be further examined in future studies.

With regard to the above associations applied to grandmothers rather than grandfathers, it is in line with a study in 10 European countries [53]. This further suggests the gender differences in depressive symptoms of grandparents looking after grandchildren. Previous empirical studies have found that grandmothers who look after grandchildren had a lower risk of developing depression and attributed this to males' more detached role in childrearing and care $[20,30]$. This may be particularly important in Chinese society, given strongly differentiated gender roles and responsibilities. The gendered difference in grandchild-care involvement suggests that grandfathers may acquire fewer psychological 
resources and benefits, but also suffer less from stress and other psychological burdens in later life because of their limited involvement in caring for grandchildren $[86,87]$. With regard to grandmothers, the increased contact with adult children during grandchild care is usually a reinforcement of the mother-child relationship and might work as another mechanism for reducing depressive symptoms. Heavy grandchild-care involvement and probable strained relationships deriving from overly frequent contact with adult children are more likely to increase role strain for grandmothers than grandfathers and, therefore, could translate into a deeper health deficit (e.g., an increase in depressive symptoms). However, further investigation, including qualitative studies, might help to determine the mechanism of the gender differences in the association between grandparental childcare and depressive symptoms.

The current study supplements and improves upon the existing literature on grandchild care and depressive symptoms among grandparents in rural China. Unlike previous studies, we employ a matching method to balance the multidimensional distribution of covariates between non-caregivers and caregivers, and thereby reduce the degree of grandchild-care dependence on estimation models and further reduce biases. Moreover, we use large-scale nationally representative data from the largest developing country (China), as compared with most previous studies in developed countries. Furthermore, we employ multilevel regression to remove the cluster effect of individuals at different levels of hierarchy in accordance with the sampling method.

\section{Limitations}

We acknowledge several limitations of the current study and, therefore, the findings should be interpreted with caution. Firstly, owing to the limited data on characteristics of grandchildren in CHARLS, we took only the number of grandchildren into consideration. Detailed characteristics of grandchildren (age, gender, health status and so on) cannot be extracted from the questionnaire, which may make estimation less precise. Secondly, we have no information regarding the experiences and assignments of grandparent caregivers. No data are available on their reasons for assuming the responsibility for grandchild care (e.g., out of a sense of obligation); the caregiving pattern (e.g., temporary or primary caregiver, custodial or non-custodial caregiver, sole caregiver or caregiver with other helpers); their feelings during care involvement; the daily matters and activities they perform; the quality of caregiving; or their relationships with their adult children. Future studies covering such information may contribute to identifying the causal pathways underlying the association between grandparental childcare and depressive symptoms, as well as gender differences. Thirdly, grandparents' self-reported caregiving hours can be subject to recall bias and socialdesirability bias [9]. Fourthly, in view of past studies indicating that grandparents in rural China are more likely to be involved in intensive caregiving [11,36], and their potential medical problems owing to a lack of healthcare resources and supporting alternative childcare facilities compared with urban areas [1], we focused on a rural sample in this study. The possible rural-urban gender differences in depressive symptoms of grandparents caring for grandchildren are needed to be identified. Such a study would contribute to detecting potential gender disparities in grandchild-care engagement and health conditions between rural and urban grandparents, and may be used to further improve policy formulation. Fifthly, although we found there to be an association between grandchild care and depressive symptoms among grandmothers rather than grandfathers, further investigation, including qualitative and quantitative studies, is needed to identify the causal mechanisms, and to assess the extent to which the observed gender differences depend on grandmothers' and grandfathers' differential roles, expectations and experiences.

In addition, we declined to use the longitudinal dataset for CHARLS to examine the gender differences in the causal relationship between grandchild care and depressive symptoms among grandparents, owing to limited grandchild information. In order to reduce biased estimation as far as possible, the present study examined only the association between grandchild care and depressive symptoms, although CEM, a quasi-experimental matching method for causal inference, was employed [88]. Based on the findings of this study, it is necessary to examine the causal relationship between grandparental caregiving patterns and depressive symptoms, as well as the gender differences, by using other, more detailed, precise and comprehensive longitudinal data related to grandchild care.

\section{Conclusion}

The present study highlights the gender differences in depressive symptoms of rural Chinese grandparents caring for grandchildren. Grandmothers suffered more from depressive symptoms than grandfathers. Grandmothers with grandchild provision, particularly at moderate intensity, were associated with fewer depressive symptoms compared with non-caregivers. We recommend that grandparents be encouraged to engage in grandchild care, but at moderate intensity. Against the background of an aging population and a potentially increasing birth rate with the implementation of the universal two-child policy in China [89], more and more elderly citizens will become involved in grandchild care in future. The mental and physical health of middle- and old-aged adults- 
and, in particular, females-should be monitored closely. Humanistic care, preventive care and curative treatment strategies focusing on middle- and old-aged females should, therefore, be developed and refined.

\section{Abbreviations}

SHARE: Survey of Health, Ageing and Retirement in Europe; CHARLS: China Health and Retirement Longitudinal Study; CES-D: Center for Epidemiologic Studies Depression Scale; CEM: Coarsened exact matching; MIB: Monotonic Imbalance Bounding; PSM: Propensity score matching; ICC: Intra-class Correlation Coefficient

\section{Supplementary Information}

The online version contains supplementary material available at https://doi. org/10.1186/s12889-021-11886-3.

Additional file 1: Table S1. The moderation effect of gender on the association between grandchild care and depressive symptoms in matched cohort.

\section{Acknowledgements}

The authors would like to thank CHARLS research and field team for collecting the data, and Peking University for providing the access to data. We also greatly appreciate helpful comments from The Youth Innovation Team of Shaanxi Universities.

\section{Authors' contributions}

DZ contributed to the overall design and conceptualization, analysis, data interpretation and original draft writing. ZZ, CS and SI contributed to the editing and revising of the manuscript. YZ and DC interpreted the statistical results. SL provided statistical analysis guidance. All authors reviewed the manuscript and approved the final manuscript for submission.

\section{Funding}

This work was supported by National Natural Science Foundation of China under Grant 71874137, and Shaanxi Social Science Foundation under Grant 20175024. The founding bodies were not involved in the design of the study or in activities related to data collection, analysis and interpretation, and manuscript writing.

\section{Availability of data and materials}

The data that support the findings of this study are openly available in CHARLS website: http://charls.pku.edu.cn.

\section{Declarations}

Ethics approval and consent to participate

Not applicable.

\section{Consent for publication}

Not applicable.

\section{Competing interests}

The authors declare that they have no competing interests.

\section{Author details}

${ }^{1}$ School of Public Policy and Administration, Xi'an Jiaotong University, No. 28 Xianning West Road, Xi'an 710049, Shaanxi, China. ${ }^{2}$ School of Public Health, Health Science Center, Xi'an Jiaotong University, Xi'an, China.

Received: 16 December 2020 Accepted: 29 September 2021

Published online: 11 October 2021

\section{References}

1. Chen F, Liu G. The health implications of grandparents caring for grandchildren in China. J Gerontol B Psychol Sci Soc Sci. 2012;67(1):99-112. https://doi.org/10.1093/geronb/gbr132.
2. Jun HJ. Educational differences in the cognitive functioning of grandmothers caring for grandchildren in South Korea. Res Aging. 2015; 37(5):500-23. https://doi.org/10.1177/0164027514545239.

3. Clottey E, Scott A, Alfonso M. Grandparent caregiving among rural African Americans in a community in the American south: challenges to health and wellbeing. Rural Remote Health. 2015;15(3):3313.

4. Fuller-Thomson E, Minkler M. African American grandparents raising grandchildren: a national profile of demographic and health characteristics. Health Soc Work. 2000;25(2):109-18. https://doi.org/10.1093/hsw/25.2.109.

5. Hayslip B Jr, Kaminski PL. Grandparents raising their grandchildren: a review of the literature and suggestions for practice. The Gerontologist. 2005;45(2): 262-9. https://doi.org/10.1093/geront/45.2.262.

6. Glaser K, Price D, Ribe E, Di Gessa G, Tinker A. Grandparenting in Europe: family policy and grandparents' role in providing childcare (summary); 2013.

7. Mtshali M. The relationship between grandparents and their grandchildren in the black families in South Africa. J Comp Fam Stud. 2015;46(1):75-83. https://doi.org/10.3138/jcfs.46.1.75.

8. Ku LJ, Stearns SC, Van Houtven CH, Lee SY, Dilworth-Anderson P, Konrad TR. Impact of caring for grandchildren on the health of grandparents in Taiwan. J Gerontol B Psychol Sci Soc Sci. 2013;68(6):1009-21. https://doi.org/10.1 093/geronb/gbt090

9. Xu H. Physical and mental health of Chinese grandparents caring for grandchildren and great-grandparents. Soc Sci Med. 2019;229:106-16. https://doi.org/10.1016/j.socscimed.2018.05.047.

10. Yu J, Xie Y. Cohabitation in China: trends and determinants. Popul Dev Rev. 2015;41(4):607-28. https://doi.org/10.1111/j.1728-4457.2015.00087.x.

11. Cong Z, Silverstein $M$. Caring for grandchildren and intergenerational support in rural China: a gendered extended family perspective. Ageing Soc. 2012;32(3):425-50. https://doi.org/10.1017/S0144686X11000420.

12. Cong $Z$, Silverstein $M$. Intergenerational time-for-money exchanges in rural China: does reciprocity reduce depressive symptoms of older grandparents? Res Hum Dev. 2008:5(1):6-25. https://doi.org/10.1080/15427600701853749.

13. Malhi GS, Mann JJ. Depression. Lancet. 2018;392(10161):2299-312. https:// doi.org/10.1016/S0140-6736(18)31948-2.

14. De Aquino JP, Londono A, Carvalho AF. An update on the epidemiology of major depressive disorder across cultures. In: Kim Y-K, editor. Understanding depression: volume 1 biomedical and neurobiological background. Singapore: Springer; 2018. p. 309-15. https://doi.org/10.1007/978-981-10-6580-4_25.

15. Lamers F, Milaneschi Y, Smit JH, Schoevers RA, Wittenberg G, Penninx BWJH. Longitudinal association between depression and inflammatory markers: results from the Netherlands study of depression and anxiety. Biol Psychiatry 2019:85(10):829-37. https://doi.org/10.1016/..biopsych.2018.12.020.

16. Gustafsson H, Nordström A, Nordström P. Depression and subsequent risk of Parkinson disease: a nationwide cohort study. Neurology. 2015;84(24): 2422-9. https://doi.org/10.1212/WNL.0000000000001684.

17. Vancampfort D, Correll CU, Galling B, Probst M, De Hert M, Ward PB, et al. Diabetes mellitus in people with schizophrenia, bipolar disorder and major depressive disorder: a systematic review and large scale meta-analysis. World Psychiatry. 2016;15(2):166-74. https://doi.org/10.1002/wps.20309.

18. Seldenrijk A, Vogelzangs N, Batelaan NM, Wieman I, van Schaik DJ, Penninx BJ. Depression, anxiety and 6-year risk of cardiovascular disease. J Psychosom Res. 2015;78(2):123-9. https://doi.org/10.1016/j.jpsychores.2014.10.007.

19. WHO. Depression and other common mental disorders: global health estimates. Geneva: World Health Organization; 2017. Contract No.: WHO/ MSD/MER/2017.2

20. Grundy EM, Albala C, Allen E, Dangour AD, Elbourne D, Uauy R. Grandparenting and psychosocial health among older Chileans: a longitudinal analysis. Aging Ment Health. 2012;16(8):1047-57. https://doi. org/10.1080/13607863.2012.692766.

21. Chung S, Park A. The longitudinal effects of grandchild care on depressive symptoms and physical health of grandmothers in South Korea: a latent growth approach. Aging Ment Health. 2018;22(12):1556-63. https://doi.org/1 $0.1080 / 13607863.2017 .1376312$

22. Tsai F-J. The maintaining and improving effect of grandchild care provision on elders' mental health — evidence from longitudinal study in Taiwan. Arch Gerontol Geriatr. 2016;64:59-65. https://doi.org/10.1016/j.archger.2016.01.009.

23. Tsai F-J, Motamed S, Rougemont A. The protective effect of taking care of grandchildren on elders' mental health? Associations between changing patterns of intergenerational exchanges and the reduction of elders' loneliness and depression between 1993 and 2007 in Taiwan. BMC Public Health. 2013;13(1):567. https://doi.org/10.1186/1471-2458-13-567. 
24. Cheng Z, Ye X. Living arrangements, caring for grandchildren, and depressive symptoms among grandparents in China. Innov Aging. 2017; 1(suppl_1):377.

25. Sieber SD. Toward a theory of role accumulation. Am Sociol Rev. 1974;39(4): 567-78. https://doi.org/10.2307/2094422.

26. Moen P, Robison J, Dempster-McClain D. Caregiving and women's wellbeing: a life course approach. J Health Soc Behav. 1995;36(3):259-73. https://doi.org/10.2307/2137342.

27. Xu L, Tang F, Li LW, Dong XQ. Grandparent Caregiving and Psychological Well-Being Among Chinese American Older Adults-The Roles of Caregiving Burden and Pressure. J Gerontol A Biol Sci Med Sci. 2017; 72(suppl_1):S56-62.

28. Minkler M, Fuller-Thomson E, Miller D, Driver D. Depression in grandparents raising grandchildren: results of a national longitudinal study. Arch Fam Med. 1997;6(5):445-52. https://doi.org/10.1001/archfami.6.5.445.

29. Hughes ME, Waite $L$, LaPierre TA, Luo Y. All in the family: the impact of caring for grandchildren on grandparents' health. J Gerontol B Psychol Sci Soc Sci. 2007;62(2):S108-S19. https://doi.org/10.1093/geronb/62.2.S108.

30. Blustein J, Chan S, Guanais F. Elevated depressive symptoms among caregiving grandparents. Health Serv Res. 2004;39(6 Pt 1):1671-89. https:// doi.org/10.1111/j.1475-6773.2004.00312.x.

31. Goode WJ. A theory of role strain. Am Sociol Rev. 1960;25(4):483-96. https:// doi.org/10.2307/2092933.

32. Pearlin LI. The sociological study of stress. J Health Soc Behav. 1989;30(3): 241-56. https://doi.org/10.2307/2136956.

33. Minkler M, Fuller-Thomson DE. Physical and mental health status of American grandparents providing extensive child care to their grandchildren. Journal of the American Medical Women's Association (1972). 2001;56(4):199-205.

34. Fuller-Thomson E, Minkler M. American grandparents providing extensive child care to their grandchildren: prevalence and profile. The Gerontologist. 2001;41(2):201-9. https://doi.org/10.1093/geront/41.2.201.

35. Zuo D, Silverstein M. Caring for grandchildren in rural China: consequences for grandparents' mental and cognitive health. Innov Aging. 2018;2(suppl_ 1):228.

36. Xu L, Wu B, Chi I, Hsiao HY. Intensity of grandparent caregiving and life satisfaction among rural Chinese older adults: a longitudinal study using latent difference score analysis. Fam Community Health. 2012;35(4):287-99. https://doi.org/10.1097/FCH.0b013e31826665d0.

37. Bordone V, Arpino B. Grandparenthood, grandchild care and depression among older people in 18 countries. J Fam Res. 2019;31(2):216-39. https:// doi.org/10.3224/zff.v31i2.06.

38. Ko PC, Hank K. Grandparents caring for grandchildren in China and Korea: findings from CHARLS and KLoSA. J Gerontol B Psychol Sci Soc Sci. 2014; 69(4):646-51. https://doi.org/10.1093/geronb/gbt129.

39. Lee J, Bauer JWS. Profiles of grandmothers providing child care to their grandchildren in South Korea. J Comp Fam. 2010;41(3):455-75. https://doi. org/10.3138/jcfs.41.3.455.

40. Bordone V, Arpino B, Aassve A. Patterns of grandparental child care across Europe: the role of the policy context and working mothers' need. Ageing Soc. 2017;37(4):845-73. https://doi.org/10.1017/S0144686X1600009X

41. Di Gessa G, Glaser K, Tinker A. The health impact of intensive and nonintensive grandchild Care in Europe: new evidence from SHARE. J Gerontol B Psychol Sci Soc Sci. 2016;71(5):867-79. https://doi.org/10.1093/ geronb/gbv055.

42. Winefield $H$, Air T. Grandparenting: diversity in grandparent experiences and needs for healthcare and support. Int J Evid Based Healthc. 2010;8(4):27783. https://doi.org/10.1111/j.1744-1609.2010.00187.x.

43. Martin-Baena D, Mayoral O. Gender differences on the psychological wellbeing of early Spanish grandparents caring for grandchildren. J Psychiatry Behav Health Forecast. 2019;2(2):1012.

44. Arpino B, Bordone V, Balbo N. Grandparenting, education and subjective well-being of older Europeans. Eur J Ageing. 2018;15(3):251-63. https://doi org/10.1007/s10433-018-0467-2

45. Chen X, Crimmins E, Hu P, Kim JK, Meng Q, Strauss J, et al. Venous bloodbased biomarkers in the China health and retirement longitudinal study: rationale, design, and results from the 2015 wave. Am J Epidemiol. 2019; 188(11):1871-7. https://doi.org/10.1093/aje/kwz170.

46. Zhao Y, Hu Y, Smith JP, Strauss J, Yang G. Cohort profile: the China health and retirement longitudinal study (CHARLS). Int J Epidemiol. 2012:43(1):618. https://doi.org/10.1093/ije/dys203.
47. Guo J, Guan L, Fang L, Liu C, Fu M, He H, et al. Depression among Chinese older adults: a perspective from Hukou and health inequities. J Affect Disord. 2017;223:115-20. https://doi.org/10.1016/j.jad.2017.07.032.

48. Ahn T, Choi KD. Grandparent caregiving and cognitive functioning among older people: evidence from Korea. Rev Econ Househ. 2019;17(2):553-86. https://doi.org/10.1007/s11150-018-9413-5.

49. Fang $Y$, Zhang Z. Migrant household homeownership outcomes in large Chinese cities - the sustained impact of hukou. Eurasian Geogr Econ. 2016; 57(2):203-27. https://doi.org/10.1080/15387216.2016.1228075.

50. Cheng ST, Chan AC. The Center for Epidemiologic Studies Depression Scale in older Chinese: thresholds for long and short forms. Int J Geriatr Psychiatry. 2005;20(5):465-70. https://doi.org/10.1002/gps.1314.

51. Cheng HG, Chen S, McBride O, Phillips MR. Prospective relationship of depressive symptoms, drinking, and tobacco smoking among middle-aged and elderly community-dwelling adults: results from the China health and retirement longitudinal study (CHARLS). J Affect Disord. 2016;195:136-43. https://doi.org/10.1016/j.jad.2016.02.023.

52. Wang R, Chen Z, Zhou Y, Shen L, Zhang Z, Wu X. Melancholy or mahjong? Diversity, frequency, type, and rural-urban divide of social participation and depression in middle- and old-aged Chinese: a fixed-effects analysis. Soc Sci Med. 2019;238:112518. https://doi.org/10.1016/j.socscimed.2019.112518.

53. Di Gessa G, Glaser K, Tinker A. The impact of caring for grandchildren on the health of grandparents in Europe: a lifecourse approach. Soc Sci Med. 2016;152:166-75. https://doi.org/10.1016/j.socscimed.2016.01.041.

54. Kim HJ. Grandparents providing care for grandchildren and employment status of grandparents in South Korea. J Women Aging. 2018;30(1):49-61. https://doi.org/10.1080/08952841.2016.1259443.

55. Wu W, Chen Y, Stephens M, Liu Y. Long working hours and self-rated health: evidence from Beijing, China. Cities. 2019;95:102401. https://doi.org/1 0.1016/j.cities.2019.102401.

56. Listyowardojo TA, Yan X, Leyshon S, Ray-Sannerud B, Yu XY, Zheng K, et al. A safety culture assessment by mixed methods at a public maternity and infant hospital in China. J Multidiscip Healthc. 2017;10:253-62. https://doi. org/10.2147/JMDH.S136943.

57. Cotten SR, Ford G, Ford S, Hale TM. Internet use and depression among retired older adults in the United States: a longitudinal analysis. J Gerontol B Psychol Sci Soc Sci. 2014;69(5):763-71. https://doi.org/10.1093/geronb/gbu018.

58. Winstead V, Anderson WA, Yost EA, Cotten SR, Warr A, Berkowsky RW. You can teach an old dog new tricks: a qualitative analysis of how residents of senior living communities may use the web to overcome spatial and social barriers. J Appl Gerontol. 2012;32(5):540-60. https://doi.org/10.1177/0733464 811431824.

59. Rubin DB. The use of matched sampling and regression adjustment to remove Bias in observational studies. Biometrics. 2006;29(1):185-203. https:// doi.org/10.2307/2529685.

60. Hametner C, Kellert L, Ringleb PA. Impact of sex in stroke thrombolysis: a coarsened exact matching study. BMC Neurol. 2015;15(1):10. https://doi. org/10.1186/s12883-015-0262-Z.

61. lacus SM, King G, Porro G. Causal inference without balance checking: coarsened exact matching. Polit Anal. 2012;20(1):1-24. https://doi.org/10.1 093/pan/mpr013.

62. lacus SM, King G, Porro G. Multivariate matching methods that are monotonic imbalance bounding. J Am Stat Assoc. 2011;106(493):345-61. https://doi.org/10.1198/jasa.2011.tm09599.

63. Zhao D, Zhou Z, Shen C, Nawaz R, Li D, Ren Y, et al. Rural and urban differences in patient experience in China: a coarsened exact matching study from the perspective of residents. BMC Health Serv Res. 2021;21(1): 330. https://doi.org/10.1186/s12913-021-06328-0.

64. Tetteh J, Kogi R, Yawson AO, Mensah G, Biritwum R, Yawson AE. Effect of self-rated health status on functioning difficulties among older adults in Ghana: coarsened exact matching method of analysis of the World Health Organization's study on global AGEing and adult health, wave 2. PLoS One. 2019;14(11):e0224327. https://doi.org/10.1371/journal.pone.0224327.

65. Green MA, Subramanian SV, Vickers D, Dorling D. Internal migration, area effects and health: Does where you move to impact upon your health? Soc Sci Med. 2015;136-137:27-34.

66. Blackwell M, lacus S, King G, Porro G. Cem: coarsened exact matching in Stata. Stata J. 2009;9(4):524-46. https://doi.org/10.1177/1536867X0900900402.

67. Tang F, Xu L, Chi I, Dong X. Psychological well-being of older ChineseAmerican grandparents caring for grandchildren. J Am Geriatr Soc. 2016; 64(11):2356-61. https://doi.org/10.1111/jgs.14455. 
68. Kamruzzaman M, Mamun ASMA, Bakar SMA, Saw A, Kamarul T, Islam MN, et al. Multilevel linear regression analysis of factors influencing body mass index among Bangladeshi married non-pregnant women. J Biosoc Sci. 2017; 49(4):498-508. https://doi.org/10.1017/S0021932016000572.

69. Park S, Lake ET. Multilevel modeling of a clustered continuous outcome: nurses' work hours and burnout. Nurs Res. 2005;54(6):406-13. https://doi. org/10.1097/00006199-200511000-00007.

70. Aassve A, Meroni E, Pronzato C. Grandparenting and childbearing in the extended family. Eur J Popul. 2012;28(4):499-518. https://doi.org/10.1007/s 0680-012-9273-2.

71. Laughlin L. Who's minding the kids? Child care arrangements: spring 2011. Washington: U.S. Census Bureau; 2013.

72. Miyawaki CE. A Review of Ethnicity, Culture, and Acculturation Among Asian Caregivers of Older Adults (2000-2012). Sage Open. 2015;5(1). https://doi. org/10.1177/2158244014566365.

73. Bordone V. Contact and proximity of older people to their adult children: a comparison between Italy and Sweden. Popul Space Place. 2009;15(4):35980. https://doi.org/10.1002/psp.559.

74. Gattai FB, Musatti TJFR. Grandmothers' involvement in Grandchildren's care: attitudes, feelings, and emotions. Fam Relat. 1999;48(1):35. https://doi.org/1 $0.2307 / 585680$

75. Xie X, Xia Y. Grandparenting in Chinese immigrant families. Marriage Fam Rev. 2011;47(6):383-96. https://doi.org/10.1080/01494929.2011.594218.

76. Kessler RC. The epidemiology of depression among women. In: Keyes CLM, Goodman SH, editors. Women and depression: a handbook for the social, behavioral, and biomedical sciences. Cambridge: Cambridge University Press; 2006. p. 22-38. https://doi.org/10.1017/CBO9780511841262.004.

77. Kockler M, Heun R. Gender differences of depressive symptoms in depressed and nondepressed elderly persons. Int J Geriatr Psychiatry. 2002; 17(1):65-72. https://doi.org/10.1002/gps.521.

78. Sonnenberg CM, Deeg DJH, van Tilburg TG, Vink D, Stek ML, Beekman ATF. Gender differences in the relation between depression and social support in later life. Int Psychogeriatr. 2013;25(1):61-70. https://doi.org/10.1017/S1 041610212001202.

79. Leach LS, Christensen H, Mackinnon AJ, Windsor TD, Butterworth P. Gender differences in depression and anxiety across the adult lifespan: the role of psychosocial mediators. Soc Psychiatry Psychiatr Epidemiol. 2008;43(12):98398. https://doi.org/10.1007/s00127-008-0388-z.

80. Lou WWQ. Depressive symptoms of older adults in Hong Kong: the role of grandparent reward. Int J Soc Welf. 2011;20(s1):S135-S47. https://doi.org/1 0.1111/j.1468-2397.2011.00814.x.

81. McGowen MR, Ladd L, Strom RD. On-line assessment of grandmother experience in raising grandchildren. Educ Gerontol. 2006;32(8):669-84. https://doi.org/10.1080/03601270500494048.

82. Sands RG, Goldberg-Glen R, Thornton PL. Factors associated with the positive well-being of grandparents caring for their grandchildren. J Gerontol Soc Work. 2005;45(4):65-82. https://doi.org/10.1300/J083v45n04_05.

83. Jendrek M. Grandparents who parent their grandchildren: effects on lifestyle. J Marriage Fam. 1993;55(3):609-21. https://doi.org/10.2307/353342.

84. Weber JA, Waldrop DP. Grandparents raising grandchildren. J Gerontol Soc Work. 2000;33(2):27-46. https://doi.org/10.1300/J083v33n02_03.

85. Pruchno R. Raising grandchildren: the experiences of black and white grandmothers. Gerontologist. 1999;39(2):209-21. https://doi.org/10.1093/ geront/39.2.209.

86. Baker $L$, Silverstein $M$. The wellbeing of grandparents caring for grandchildren in China and the United States. In: Arber S, Timonen V, editors. Contemporary grandparenting: changing family relationships in global contexts. Bristol: Policy Press; 2012. p. 51-70. https://doi.org/10.1332/ policypress/9781847429681.003.0003.

87. Reynolds GP, Wright JV, BJJoIP B. The roles of grandparents in educating Today's children. J Instr Psychol. 2003;30(4):316-25.
88. Si Y, Zhou Z, Su M, Hu H, Yang Z, Chen X. Comparison of health care utilization among patients affiliated and not affiliated with healthcare professionals in China. BMC Health Serv Res. 2020;20(1):1118. https://doi. org/10.1186/s12913-020-05895-y.

89. Yan J, Wang L, Yang Y, Zhang Y, Zhang H, He Y, et al. The trend of caesarean birth rate changes in China after 'universal two-child policy' era: a population-based study in 2013-2018. BMC Med. 2020;18(1):249. https://doi. org/10.1186/s12916-020-01714-7.

\section{Publisher's Note}

Springer Nature remains neutral with regard to jurisdictional claims in published maps and institutional affiliations.

\section{Ready to submit your research? Choose BMC and benefit from:}

- fast, convenient online submission

- thorough peer review by experienced researchers in your field

- rapid publication on acceptance

- support for research data, including large and complex data types

- gold Open Access which fosters wider collaboration and increased citations

- maximum visibility for your research: over $100 \mathrm{M}$ website views per year

At BMC, research is always in progress.

Learn more biomedcentral.com/submissions 